\title{
Intellectual and conceptual acquisition in retarded children: A follow-up study*
}

\author{
LEONARD I. JACOBSON, GUILLERMO BERNAL $\dagger$, \\ LARRY E. GREESON, JOHN J. RICH \\ and \\ JIM MILLHAM $\dagger \dagger$ \\ University of Miami, Coral Gables, Fla. 33124
}

Institutionalized retarded children participated in a follow-up study 13 months after their participation in a behavior modification program. The objective of the original experimental program was to provide training in the acquisition of conceptual and intellectual skills. The program employed the use of modeling, information feedback, and social and material reinforcement. A control condition was evaluated also, in which Ss received $10 \mathrm{~h}$ of social interaction but no experimental training. It was found that Ss who participated previously in the experimental program functioned at a high level on the concept attainment task. In addition, the original gains in IQ reported for the Ss in the experimental condition were retained, and the initially severely retarded Ss continued to increase their IQ scores during the 13-month interval.

In a previous study, Jacobson, Kellogg, Greeson, \& Bernal (1973) reported the results of an investigation in which a behavior modification program was administered to mildly, moderately, and severely retarded institutionalized children. The experimental treatment was a revised version of a concept acquisition program employed previously with preschool children from poverty backgrounds that provided training in "learning how to learn" (Jacobson, Berger, Bergman, Millham, \& Greeson, 1971; Jacobson \& Greeson, 1972).

Two experimental conditions were employed in the study by Jacobson, Kellogg, et al (1973). The Ss participated in either a modeling condition, in which correct responding was modeled for the Ss prior to their responding, or a feedback condition, in which correct performance was modeled for the Ss immediately after their responding. It was found that participation in both experimental conditions resulted in the rapid acquisition of learning sets for moderately and severely retarded Ss. In addition, Ss across conditions demonstrated significant increases in measured intelligence, with the greatest increases-over six points-occurring for the severely retarded Ss.

The present study reports the results of a 13-month follow-up study that evaluated the durability of the effects obtained for Ss differing in their initial degree of retardation.

*This study was supported by Research Grant NGL 10-007-010 from the National Aeronautics and Space Administration.

+ Now at the University of Massachusetts, Amherst.

$+\uparrow$ Now at the University of Houston.

\section{METHOD \\ Subjects}

The Ss were 25 retarded children residing at the Sunland Training Center at Miami, a large state institution in southern Florida. The mean age of the $S s$ was 118.28 months $(\mathrm{SD}=21.72)$; the mean initial IQ of the $\mathrm{Ss}$ was 38.80 $(S D=10.05)$. The mean period of time between completion of the original study and the follow-up was 13.40 months $(\mathrm{SD}=7.49)$.

The Ss were divided on the basis of their scores on the initial IQ administration. Ss with IQ scores between 46 and 59 comprised the high-IQ group; Ss with scores between 34 and 45 comprised the medium group; Ss with scores between 25 and 33 comprised the low-IQ group.

Of the 26 participants in the original experiment, 17 still resided in the institution at the time the follow-up investigation was conducted. These $17 \mathrm{Ss}$ constituted the present experimental group. Eight additional Ss were employed in the present study as a control group. These Ss were administered the Stanford-Binet and the concept attainment task in the same manner and at the same time as the $S s$ in the experimental condition.

\section{Original Training}

In the original study, the Ss participated in either a modeling condition, in which correct responding was modeled for the Ss prior to their responding, or a feedback condition, in which correct performance was modeled for the Ss immediately after they responded. For purposes of comparison, a control condition was employed also, and Ss in this condition did not participate in the experimental program.

In a previous investigation, Jacobson, Berger, et al (1971) demonstrated that social interaction effects influence greatly the results obtained in many behavioral studies. In order to demonstrate more adequately the effectiveness of the experimental program apart from these interaction effects, the Ss in the control condition were given $10 \mathrm{~h}$ of social interaction with the Es, but no systematic training of any kind was provided during this time period. The Stanford-Binet Intelligence Scale was administered to all Ss before and after participation in either condition.

\section{Measures Administered in the Follow-Up Study}

In the present study, all of the Ss were administered the Stanford-Binet Intelligence Scale and the Concept Development Test (CDT). The CDT was a measure of conceptual functioning devised by the investigators and consisted of 15 two-choice concept problems with 10 trials for each problem. Five of the correct concepts were one-dimensional (e.g., green), five were two-dimensional (e.g., small triangle), and five were three-dimensional (e.g., one blue circle).

The Ss were asked to point to the correct instance of the concept but were not informed as to the correctness of their response. The Ss were encouraged to participate but were not administered reinforcement for correct responding. The two-choice instances of the multidimensional concept problems were constructed so that the Ss could not respond correctly unless they discriminated both of the elements of the correct concept.

In the original study, no significant differences in performance were found for $S s$ in the two experimental conditions. Accordingly, the Ss in both conditions were considered together 
Table 1

Effects of Condition and Initial IQ Level on IQ Scores

\begin{tabular}{|c|c|c|c|c|c|c|c|c|}
\hline \multirow[b]{2}{*}{ Condition } & \multirow[b]{2}{*}{$\mathbf{N}$} & \multicolumn{2}{|c|}{ Pre-IQ } & \multicolumn{2}{|c|}{ Post-IQ } & \multicolumn{2}{|c|}{ Follow-Up IQ } & \multirow{2}{*}{$\begin{array}{c}\text { Pre- } \\
\text { Follow-Up } \\
\text { Difference }\end{array}$} \\
\hline & & Mean & SD & Mean & SD & Mean & SD & \\
\hline $\begin{array}{l}\text { Experimental } \\
\text { High IQ } \\
\text { Medium IQ } \\
\text { Low IQ }\end{array}$ & $\begin{array}{r}17 \\
5 \\
6 \\
6\end{array}$ & $\begin{array}{l}54.60 \\
37.17 \\
29.00\end{array}$ & $\begin{array}{l}5.32 \\
2.99 \\
3.16\end{array}$ & $\begin{array}{l}58.20 \\
40.67 \\
35.67\end{array}$ & $\begin{array}{l}6.87 \\
6.31 \\
1.37\end{array}$ & $\begin{array}{l}54.20 \\
41.17 \\
39.33\end{array}$ & $\begin{array}{l}6.26 \\
2.99 \\
2.94\end{array}$ & $\begin{array}{r}-0.40 \\
4.00 \\
10.33\end{array}$ \\
\hline $\begin{array}{l}\text { Control } \\
\text { High IQ } \\
\text { Medium IQ } \\
\text { Low IQ }\end{array}$ & $\begin{array}{l}8 \\
2 \\
3 \\
3\end{array}$ & $\begin{array}{l}48.50 \\
36.00 \\
31.67\end{array}$ & $\begin{array}{l}0.71 \\
2.00 \\
1.53\end{array}$ & $\begin{array}{l}48.50 \\
38.33 \\
33.67\end{array}$ & $\begin{array}{l}2.12 \\
5.86 \\
0.58\end{array}$ & $\begin{array}{l}47.50 \\
38.67 \\
32.67\end{array}$ & $\begin{array}{l}0.71 \\
5.03 \\
1.16\end{array}$ & $\begin{array}{r}-1.00 \\
2.67 \\
1.00\end{array}$ \\
\hline
\end{tabular}

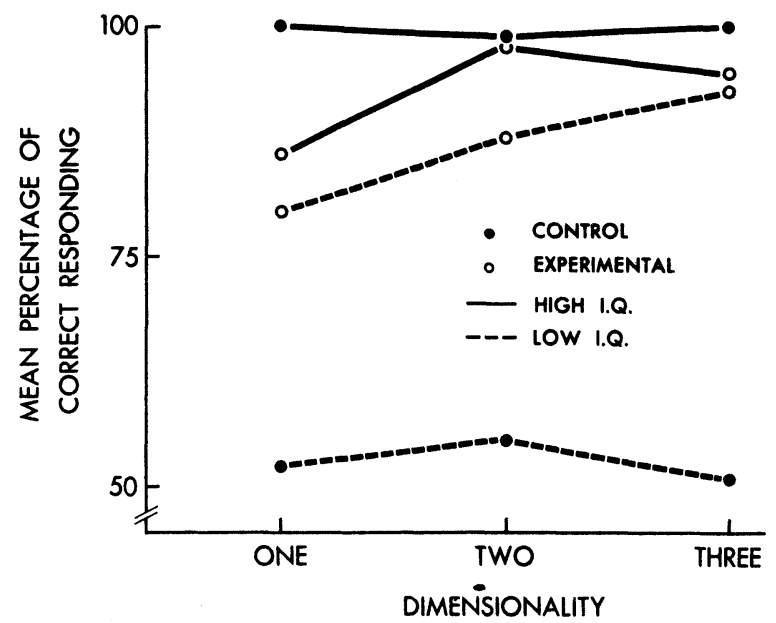

Fig. 1. Effects of condition and initial IQ on concept attainment.

and designated as the experimental group in the present study. The results obtained for this group were compared with those obtained for the control Ss.

\section{RESULTS}

\section{Concept Attainment}

An analysis of variance was performed on the effects of condition and initial IQ level on the number of correct responses given for the one-, two-, and three-dimensional problems. Significant effects of condition $[F(1,19)=10.91, p<.004]$, initial IQ $[\mathrm{F}(2,19)=5.75, \mathrm{p}<.01]$, and a Condition by IQ interaction $[\mathrm{F}(2,19)=6.15, \mathrm{p}<.009]$ were in evidence. These effects are evident in Fig. 1, which portrays the mean percentage of correct responses for the one-, two-, and three-dimensional problems for experimental and control Ss of high and low IQ. It is apparent that the experimental Ss and high-IQ control Ss performed at a level of over $80 \%$ correct responding. In contrast, low-IQ control Ss responded at close to the chance level (50\%). These findings indicate that participation in the experimental programs was most beneficial for Ss of initially low IQ.

\section{Changes in IQ}

In Table 1 are presented the means and standard deviations of scores on the three IQ administrations for Ss in the experimental and control conditions initially of high, medium, or low IQ. An analysis of variance of the change in performance between the pre-IQ and the follow-up IQ administrations indicated significant effects of condition $[F(1,19)=6.40, p<.02]$, initial IQ $[F(2,19)=10.14, \quad p<.001]$, and a significant Condition by IQ interaction $[\mathrm{F}(2,19)=3.54, \mathrm{p}<.05]$.

It is apparent from the table that increases in IQ occurred in the experimental condition but not in the control condition. Within the experimental condition, no significant change in IQ was found for Ss initially of high IQ $[F(1,3)=.13]$. However, a significant increase was found for Ss initially of medium IQ $[F(1,4)=14.05$, $\mathrm{p}<.02]$ and low IQ $[\mathrm{F}(1,4)=21.24, \mathrm{p}<.01]$. Thus, the lower the initial IQ level, the greater the change that occurred in IQ scores.

The table presents also the changes between the post-IQ and the follow-up administrations. No significant change in IQ scores in the experimental condition was found for Ss initially of high $[F(1,3)=6.92]$ or medium IQ $[F(1,4)=.07]$. However, a significant increase in IQ was found for Ss initially of low IQ $[F(1,4)=10.52, p<.03]$. The pre-post gain of over 6 points for Ss initially of low IQ increased to over 10 points on the follow-up administration. Thus, the initial IQ gains of the high- and medium-IQ experimental Ss did not decrease significantly on the follow-up administration, and Ss initially of low IQ actually continued to show further gains during the 13-month interval.

\section{DISCUSSION}

These results provide further evidence that participation in systematic behavior modification programs may result in considerable and enduring improvement in the intellectual and conceptual functioning of retarded children. Program participants continued to respond with over $80 \%$ correct responses to one-, two-, and three-dimensional conceptual problems in the follow-up study. These results provide evidence that the skills acquired in conceptual problem solving did not extinguish but were reflected in the children's behavior 13 months later.

Consistent with this interpretation is the finding that the intellectual functioning of the severely retarded Ss continued to improve between the post-IQ and the follow-up administrations. It should be noted that initially these children demonstrated the 
greatest gains of any $S$ group. In the follow-up study, they continued to increase these gains in the absence of further training. These data provide further evidence that the initial program resulted in the acquisition of general strategies of problem solving that continued to improve the children's functioning and to generate environmental reinforcement long after program completion.

\section{REFERENCES}

Jacobson, L. I., Berger, S. E., Bergman, R. L., Millham, J., \& Greeson, L. E. Effects of age, sex, systematic conceptual learning, acquisition of learning sets, and programmed social interaction on the intellectual and conceptual development of preschool children from poverty backgrounds. Child pevelopment, 1971, 42, 1399-1415.

Jacobson, L. I., \& Greeson, L. E. Effects of systematic conceptual learning on the intellectual development of preschool children from poverty backgrounds: A follow-up study. Child Development, 1972, 43, 1111-1115.

Jacobson, L. I., Kellogg, R. W., Greeson, L. E., \& Bernal, G. Programming the intellectual and conceptual development of retarded children with behavioral techniques. In R. D. Rubin, H. Fensterheim, and L. P. Ullmann (Eds.), Advances in behavior therapy. New York and London: Academic Press, 1973 , in press.

(Received for publication February 23, 1973.) 